\title{
Transpapillary biliary stenting is a risk factor for pancreatic stones in patients with autoimmune pancreatitis
}

Authors

Institutions
Hiroyuki Matsubayashi' ${ }^{1}$, Yoshihiro Kishida ${ }^{1}$, Tomohiro Iwai ${ }^{1}$, Katsuyuki Murai ${ }^{1}$, Masao Yoshida $^{1}$, Kenichiro Imai ${ }^{1}$, Yusuke Yamamoto ${ }^{2}$, Masataka Kikuyama ${ }^{3}$, Hiroyuki Ono ${ }^{1}$

${ }^{1}$ Division of Endoscopy, Shizuoka Cancer Center, Shizuoka, Japan

2 Division of Hepato-Biliary-Pancreatic Surgery, Shizuoka Cancer Center, Shizuoka, Japan

${ }^{3}$ Division of Gastroenterology, Shizuoka General Hospital, Shizuoka, Japan submitted 26. August 2015 accepted after revision 13. June 2016

\section{Bibliography}

DOI http://dx.doi.org/

10.1055/s-0042-111201

Published online: 8.8.2016

Endoscopy International Open 2016; 04: E912-E917

(c) Georg Thieme Verlag KG Stuttgart · New York

E-ISSN 2196-9736

\section{Corresponding author} Hiroyuki Matsubayashi,

\section{MD, PhD}

Division of Endoscopy

Shizuoka Cancer Center 1007

Shimonagakubo

Nagaizumi

Suntogun

Shizuoka

411-8777

Japan

Fax: +81-55-9895222

h.matsubayashi@scchr.jp
Background and study aim: Pancreatic stones occasionally develop in autoimmune pancreatitis (AIP), often worsen endocrine and exocrine functions, and occasionally cause pain attacks. However, the risks of pancreatic stones in AIP have been poorly studied. The aim of this study was to analyze the risk factors associated with pancreatic stone formation in cases of AIP.

Patients and methods: In total, 50 patients with AIP (39 males, 11 females; mean age 64.0 years), followed up for at least a year, were analyzed for their demographic and clinical findings and pancreatic stone occurrence.

Results: In total, 50 patients were followed up for an average of $59.7(12-120)$ months, with steroid treatment in 44 patients ( $88 \%$ ); pancreatic stones occurred in $14(28 \%)$ patients after the diagnosis of AIP and endoscopic treatment was needed in one

\section{Introduction}

$\nabla$

Autoimmune pancreatitis (AIP), a unique subtype of chronic pancreatitis associated with autoimmune disorders, is characterized by pancreatic enlargement and narrowing of the pancreatic duct $[1,2]$. The swollen pancreas in the active phase of the disease is histologically characterized by abundant infiltrations of inflammatory cells (IgG4-positive lymphoplasmacytes in type 1 AIP and granulocytes in type 2 AIP), edema, and dense proliferative fibrosis (so-called "storiform fibrosis" in type 1 AIP) [2-4]. AIP in its active phase often causes pancreatic and peripancreatic changes typical of chronic pancreatitis (CP), such as jaundice due to bile duct oppression [1], leftsided portal hypertension due to peripancreatic venous involvements [5], and sometimes the development of pseudocysts [6], These CP-like changes respond effectively to corticosteroids and a steroid response can usually be obtained within the initial 2 weeks $[7,8]$. patient with pain attack. The pancreatic stones appeared only in patients with long follow-up period $(P<0.001,83.9$ months vs. 49.6 months), biliary stenting (odds ratio [OR]: $8.40, P=0.010$ ), relapse (OR: $6.20, P=0.023$ ), jaundice (OR: $5.40, P=0.019$ ), and swelling of the duodenal major papilla (OR: $4.67, P=0.040$ ). Biliary stenting was placed for an average of 9.9 months in 27 patients. Multivariate analysis revealed a significant association only with biliary stenting $(P=0.011)$. The stones appeared relatively earlier in patients with stones in the main pancreatic duct or Santorini duct (22.1 months) than in patients where pancreatic stones developed elsewhere (53.4 months) $(P=0.018)$.

Conclusions: The risk of pancreatic stone development should be taken into account when a biliary stent is placed in patients with AIP.

Pancreatic stones are one of the key features often demonstrated not only in the course of common $\mathrm{CP}$ but also in AIP; they are rather problematic as they are associated with worsening of both endocrine $[9,10]$ and exocrine [11 - 13] functions over the long-term and resistant to steroid therapy. Some cases with pancreatic stones are symptomatic and therefore need treatment by extracorporeal shock wave lithotripsy [14], with or without pancreatic stent placement. Patients with AIP show pancreatic stone development in $18-41 \%$ of cases [11,15], especially in the advanced phase [14] or burned-out phase of AIP [3]. Therefore, the risk factors for pancreatic stones need to be clarified to improve the long-term of quality of life in patients with AIP. To date, risk factors have only been reported in a few studies and include relapse, narrowing of both Wirsung and Santorini ducts, and high alcohol consumption $[11,15,16]$. However, the reported incidence of pancreatic stones and their risk factors vary in each report $[11,15]$, indicating that the causes of pancreatic stones may be substantially affected by the insti- 
Table 1 Comparison of cases with autoimmune pancreatitis between with or without a pancreatic stone.

\begin{tabular}{|c|c|c|c|c|c|c|c|}
\hline & \multicolumn{2}{|c|}{ Pancreatic stone } & \multicolumn{2}{|c|}{ Univariate analysis } & \multicolumn{3}{|c|}{ Multivariate analysis } \\
\hline & $+(n=14)$ & $-(n=36)$ & Odds ratio & $P$ value & Odds ratio & $95 \% \mathrm{Cl}$ & $P$ value \\
\hline Age, years & $63.4 \pm 9.0$ & $64.3 \pm 8.6$ & - & 0.582 & & & \\
\hline Sex (male/female) & $12: 2$ & $27: 9$ & 2.00 & 0.705 & & & \\
\hline \multicolumn{8}{|l|}{ Drinking alcohol } \\
\hline$>100 \mathrm{~g} /$ week & 7 & 13 & 1.77 & 0.522 & & & \\
\hline$>350 \mathrm{~g} /$ week & 3 & 2 & 4.64 & 0.126 & & & \\
\hline Smoking & 12 & 25 & 2.64 & 0.303 & & & \\
\hline Jaundice & 9 & 9 & 5.40 & 0.019 & & & \\
\hline Abdominal/back pain & 5 & 16 & 0.69 & 0.752 & & & \\
\hline Diabetes at onset & 6 & 19 & 0.67 & 0.754 & & & \\
\hline Serum amylase, U/L & $72.0 \pm 25.1$ & $117.3 \pm 149.7$ & - & 0.888 & & & \\
\hline Serum IgG, mg/dL & $1770.1 \pm 318.9$ & $1868.9 \pm 761.1$ & - & 0.804 & & & \\
\hline Serum IgG4, mg/dL & $411.7 \pm 250.8$ & $378.7 \pm 358.9$ & - & 0.342 & & & \\
\hline Serum IL-2 receptor, $\mathrm{U} / \mathrm{mL}$ & $958.2 \pm 673.7$ & $684.4 \pm 295.1$ & - & 0.315 & & & \\
\hline Macroscopic type (D:F) ${ }^{1}$ & $6: 8$ & $15: 21$ & 1.05 & 1.000 & & & \\
\hline Extrapancreatic lesion & 7 & 14 & 1.57 & 0.534 & & & \\
\hline $\begin{array}{l}\text { Narrowings of both Wirsung } \\
\text { and Santorini ducts }\end{array}$ & 12 & 22 & 3.82 & 0.175 & & & \\
\hline Swelling of papilla of Vater & 8 & 8 & 4.67 & 0.040 & & & \\
\hline Biliary stent placement & 12 & 15 & 8.40 & 0.010 & 8.40 & $1.63-43.18$ & 0.011 \\
\hline Oral steroid therapy & 13 & 31 & 2.10 & 0.663 & & & \\
\hline Pancreatic shrinkage ratio ${ }^{2}$ & $0.61 \pm 0.11$ & $0.70 \pm 0.16$ & - & 0.058 & & & \\
\hline Pancreatic atrophy ${ }^{3}$ & 5 & 8 & 1.94 & 0.474 & & & \\
\hline Relapse & 7 & 5 & 6.20 & 0.023 & & & \\
\hline Follow-up period, months ${ }^{4}$ & $83.9 \pm 21.8$ & $49.6 \pm 26.8$ & - & $<0.0001$ & & & \\
\hline
\end{tabular}

1 D: diffuse-type, F: focal-type.

${ }^{2}$ Ratio of the maximum thickness of the pancreatic lesion determined by enhanced computed tomography at initial diagnosis and at remission (or at 3-6 months after steroid initiation).

$3<1 \mathrm{~cm}$ of the pancreatic thickness in more than half of the pancreas at remission.

${ }^{4}$ In multivariate analysis, $\geq 60$ months of follow-up period was determined for the risk of pancreatic stone development; however, this was not proven to be significant.

tutional strategy in the management of AIP. We have retrospectively studied the risk factors for pancreatic stones and the characteristics of AIP cases with pancreatic stones in a single tertiary hospital.

\section{Patients and methods}

\section{Patients}

This study included 50 patients with AIP (39 male and 11 female, $64.0 \pm 8.6$ [ $45-83]$ years old), who had sufficient pancreatograms obtained by endoscopic retrograde cholangiopancreatography (ERCP) and who were followed up for at least a year without undergoing pancreatic surgery. The patients were part of a cohort of 62 patients with AIP diagnosed by International Consensus Diagnostic Criteria (ICDC) [2] at Shizuoka Cancer Center between April 2004 and April 2016. Eight patients were excluded as they were surgically treated, followed for less than a year, or underwent chemotherapy. Another four patients who already had pancreatic stones at the initial diagnosis were also excluded. Of the 50 patients, 48 were diagnosed as definitive type 1 AIP, one patient as probable type 1 AIP, and one patient as probable type 2 AIP. Endoscopic ultrasonography guided-fine needle aspiration biopsy was performed using a 22-gauge needle in 49 patients (98\%); however, no patient was definitively diagnosed as AIP from only the histology of obtained materials [17]. Forty-four $(88 \%)$ of the 50 patients underwent oral steroid therapy and were followed up for an average of 59.7 months (range: $12-120$ months). Twenty-nine patients were diagnosed as focal-type AIP and the remaining 21 patients as diffuse-type. At the initial diagnosis, all 50 patients with AIP underwent serum blood glucose tests, urine glucose positivity tests, abdominal ultrasonography (US), and dynamic computed tomography (CT) (2 mm-thickness, multi-detector) [5].

\section{Candidate factors analyzed for the risk of pancreatic stones}

Factors analyzed for the risk of pancreatic stones included age, sex, alcohol intake (low and high amount of alcohol consumption: $\geq 100 \mathrm{~g} /$ week and $\geq 350 \mathrm{~g} /$ week [11], respectively), smoking ( $\geq 10$ cigarettes/day, including past history), jaundice $(\geq 3 \mathrm{mg} / \mathrm{dL}$ of serum total bilirubin), abdominal and back pain, diabetes mellitus (serum $\mathrm{HbA} 1 \mathrm{c}>6.2 \%$ or positive urine glucose at fasting), serum amylase (normal: $43-125 \mathrm{U} / \mathrm{L}$ ), IgG (normal: $<1800 \mathrm{mg} / \mathrm{dL}$ ), IgG4 (normal: $4.8-135 \mathrm{mg} / \mathrm{dL}$ ), soluble IL-2 receptor (sIL2 R) (normal: $220-530 \mathrm{U} / \mathrm{mL}$ ), macroscopic type (focal-type or diffuse-type), extra pancreatic lesions, narrowing of both Santorini and Wirsung ducts [15], endoscopic transpapillary biliary stenting [18] (caliber size and period of stent placement), and swelling of the papilla of Vater [19]. These factors were all evaluated at the initial diagnosis ( $\bullet$ Table $\mathbf{1})$.

Steroid therapy [7], pancreatic shrinkage ratio, pancreatic atrophy [11], and relapse $[16,20]$ were also analyzed. The pancreatic shrinkage ratio was defined as the ratio of maximum thickness of the lesion of AIP measured on enhanced CT before and after the steroid therapy (3-6 months after steroid initiation / before steroid therapy) ( $\bullet$ Fig. 1). In patients without steroid therapy, pancreatic shrinkage ratio was similarly determined by the CT 

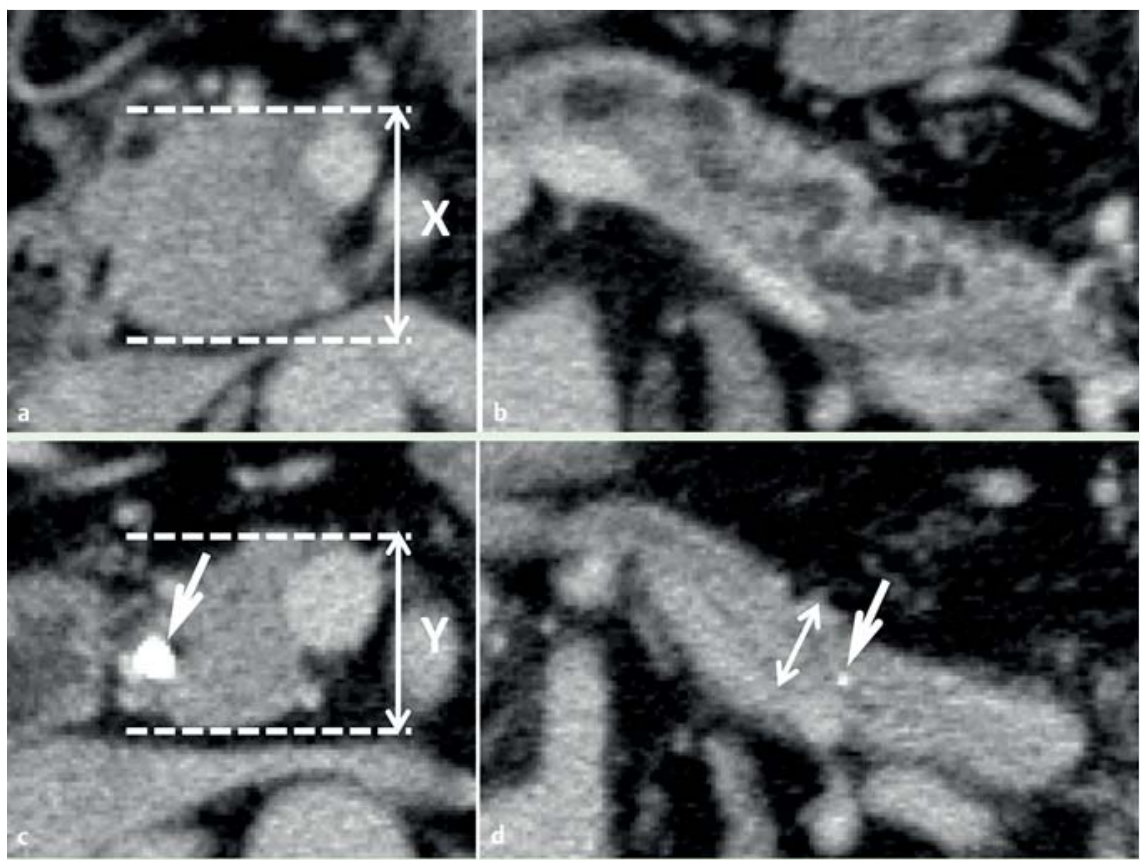

Fig. 1 CT view of autoimmune pancreatitis before and after steroid therapy (Patient 4 in $\bullet$ Table 3 ). a, b At initial diagnosis, the pancreatic head was focally enlarged, with maximum thickness of the lesion indicated by $X(a)$, and no pancreatic stones were recognized in the pancreas body (b). c Three months after steroid initiation, the thickness of the pancreatic head lesion was reduced $(\mathrm{Y})$, and the pancreatic shrinkage ratio (0.73) was calculated by $X / Y$ (arrowhead indicating a biliary stent). d A small calcification (arrowhead) was already recognized in the atrophic pancreas at the pancreatic body (length of the double-headed arrow indicating $9.3 \mathrm{~mm}$ ). e Two years after steroid initiation, pancreatic stones had increased in number within the main pancreatic duct. $\mathbf{f}$ Six years after steroid initiation, pancreatic stones had increased in size associated with the advanced level of pancreatic atrophy.
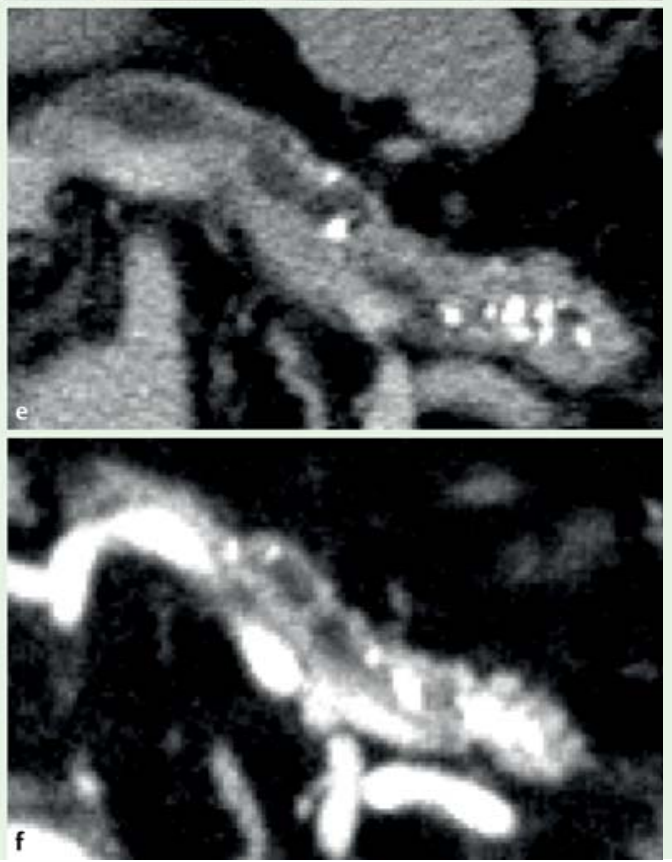

images at initial diagnosis and at remission in the course of follow-up (usually a year after diagnosis). Pancreatic atrophy was also determined from the CT images at 3-6 months after steroid initiation or at remission, where atrophy was defined as a pancreatic thickness $<1 \mathrm{~cm}$ in more than half of the pancreas [11] ( $\bullet$ Fig. 1). Relapse was defined as recurrence of existing lesions or new image-visible lesions developing during the clinical course, as well as non-visible findings such as immunologic thrombocytopenic purpura [21], which is believed to be associated with activated autoimmunity ( $\bullet$ Table 1$)$.

\section{Placement and withdrawal of biliary stents}

Biliary stent was indicated when the patients' blood tests revealed marked elevation of total bilirubin $(\geq 3 \mathrm{mg} / \mathrm{dL})$ and/or hepatobiliary enzymes, and biliary stricture was confirmed by endoscopic retrograde cholangiography. All biliary stents were endoscopically inserted without endoscopic sphincterotomy to prevent Oddi's sphincter dysfunction, which may cause future reflux cholangitis. We recommended our patients for the withdrawal of biliary stent at 3-6 months after steroid initiation with confirmation of steroid response by CT images; however, actual timing of stent removal was mostly delayed for patients' convenience ( Table 2 ). Biliary stent was removed with confirmation of improvement of biliary duct's stricture by ERCP.

\section{Diagnosis and treatment of pancreatic stones}

A pancreatic stone was diagnosed as a bone-level high density lesion depicted by plain $\mathrm{CT}$, viewed at the initial diagnosis, again at 3-6 months and 1 year after steroid initiation, and at least once in every following year. For pancreatic stone-positive patients, the period until occurrence, location (main pancreatic duct [MPD]/ Santorini duct or branch duct/pancreatic parenchyma), and number (small number: $1-3$, moderate: $4-6$, large: $\geq 7$ ) of pancreatic stones and their treatments were also summarized ( $\bullet$ Table 3 ). 
Table 2 Caliber size and period of biliary stent placement by existence of a pancreatic stone.

\begin{tabular}{|llll|}
\hline Biliary stent & \multicolumn{2}{l}{ Pancreatic stone } & P value \\
\hline \multicolumn{1}{l}{$+(\mathbf{n = 1 2})$} & $-(\mathbf{n}=\mathbf{1 5})$ & \\
\hline Caliber size, Fr. & & & \\
\hline 10 & 2 & 0 & 0.480 \\
\hline 8.5 & 9 & 7 & \\
\hline 7 & 1 & 8 & \\
\hline Period of placement, months & $9.0 \pm 6.8$ & $10.6 \pm 10.0$ & 0.845 \\
\hline
\end{tabular}

\section{Statistical analysis}

Continuous variables were compared by the Mann-Whitney $U$ test (two-sided), and nominal variables were compared by Fisher's test for univariate analysis. Candidate risk factors recognized as significant by univariate analysis were determined by multivariate analysis. For multivariate analysis, the logistic regression test (simultaneous method and stepwise method) was used. Univariate statistical analysis was performed using JavaStat, and multivariate analysis by SPSS ver. 19 (IBM, Tokyo, Japan). A probability value $<0.05$ was evaluated as statistically significant.

\section{Results}

$\nabla$

Incidence of pancreatic stones in patients with AIP

Of the 50 patients with AIP followed up for $>1$ year in our hospital, pancreatic stones were detected in 14 (28\%); 13 of these pa- tients (93\%) underwent steroid therapy. The four patients with pancreatic stones detected at the initial diagnosis of AIP were not included in these data.

Factors associated with pancreatic stone development As shown in 0 Table 1, jaundice, swelling of the papilla of Vater, biliary stent placement, relapse, and follow-up period were significant factors associated with pancreatic stone occurrence (jaundice: $64 \%[9 / 14]$ in stone $[+]$ group vs. $25 \%[9 / 36]$ in stone [-] group, odds ratio $[\mathrm{OR}]=5.40, P=0.019$; swelling of the duodenal major papilla: $57 \%$ [8/14] vs. $22 \%$ [8/36], OR=4.67, $P=0.040$; biliary stent placement: $86 \%$ [12/14] vs. $42 \%$ [15/36], $O R=8.40$, $P=0.010$; relapse: $50 \%$ [7/14] vs. $14 \%[5 / 36], O R=6.20, P=0.023$; follow-up period: $83.9 \pm 21.8$ months vs. $49.6 \pm 26.8$ months, $P<0.001)$. The breakdown of relapse was as follows: pancreatic enlargement (4), IgG4-related thrombophlebitis (1) and immunologic thrombocytopenic purpura [21] (1) in patients with pancreatic stones, and pancreatic enlargement (3), lachrymal gland swelling (1), hilar bile duct stenosis (1) and periaortitis (1) in patients without pancreatic stones. Either low amounts $(\geq 100 \mathrm{~g} /$ week) or high amounts ( $\geq 350 \mathrm{~g} /$ week [11]) of alcohol consumption were predominant in the pancreatic stone $(+)$ group compared to the pancreatic stone (-) group, but the differences were not statistically significant $(P=0.522$ and 0.126 , respectively). Narrowing of both Wirsung and Santorini ducts was recognized more frequently in the pancreatic stone (+) group (86\%) than in the pancreatic stone (-) group (61\%), but the differences were not statistically significant $(P=0.175)$ ( $\bullet$ Table 1$)$.

Table 3 Clinical findings and management of 14 patients developing a pancreatic stone.

\begin{tabular}{|c|c|c|c|c|c|c|c|c|c|c|c|c|}
\hline \multirow{2}{*}{$\begin{array}{l}\text { Patient } \\
\text { no. }\end{array}$} & \multirow[t]{2}{*}{ Age/sex } & \multicolumn{3}{|c|}{ Biliary stenting } & \multirow{2}{*}{$\begin{array}{l}\text { Swelling } \\
\text { of papilla } \\
\text { of Vater }\end{array}$} & \multirow{2}{*}{$\begin{array}{l}\text { Steroid } \\
\text { therapy }\end{array}$} & \multirow[t]{2}{*}{ Relapse } & \multicolumn{3}{|c|}{ Pancreatic stone occurrence } & \multirow{2}{*}{$\begin{array}{l}\text { Pain } \\
\text { attack }\end{array}$} & \multirow{2}{*}{$\begin{array}{l}\text { Therapy for } \\
\text { pancreatic } \\
\text { stone }\end{array}$} \\
\hline & & $\begin{array}{l}\text { Size, } \\
\text { Fr. }\end{array}$ & Type $^{1}$ & $\begin{array}{l}\text { Duration, } \\
\text { months }\end{array}$ & & & & $\begin{array}{l}\text { Timing }{ }^{2} \text {, } \\
\text { months }\end{array}$ & Site $^{3}$ & Number $^{4}$ & & \\
\hline 1 & $55 / M$ & 10 & $\mathrm{~F}$ & 25.4 & $(+)$ & $(+)$ & $(-)$ & 15 & $\begin{array}{l}\text { SD, } \\
\text { branch }\end{array}$ & Large & $(-)$ & $(-)$ \\
\hline 2 & $64 / M$ & 8.5 & $\mathrm{~F}$ & 5.8 & $(+)$ & $(+)$ & $(+)$ & 7 & $\begin{array}{l}\text { SD, } \\
\text { branch }\end{array}$ & Small & $(-)$ & $(-)$ \\
\hline 3 & $58 / M$ & 8.5 & $\mathrm{~F}$ & 6.2 & $(+)$ & $(+)$ & $(+)$ & 14 & $\begin{array}{l}\text { MPD, } \\
\text { branch }\end{array}$ & Large & $(-)$ & $(-)$ \\
\hline 4 & $55 / M$ & 8.5 & $\mathrm{~F}$ & 3.5 & $(-)$ & $(+)$ & $(-)$ & 4 & $\begin{array}{l}\text { MPD, } \\
\text { branch }\end{array}$ & Large & $(-)$ & $(-)$ \\
\hline 5 & $61 / M$ & 8.5 & $\mathrm{~F}$ & 5.2 & $(-)$ & $(+)$ & $(+)$ & 87 & $\begin{array}{l}\text { MPD, } \\
\text { branch }\end{array}$ & Large & $(-)$ & $(-)$ \\
\hline 6 & $77 / M$ & $(-)$ & $(-)$ & $(-)$ & $(+)$ & $(-)$ & $(-)$ & 12 & $\begin{array}{l}\text { MPD, } \\
\text { branch }\end{array}$ & Moderate & $(-)$ & $(-)$ \\
\hline 7 & $71 / M$ & $(-)$ & $(-)$ & $(-)$ & $(-)$ & $(+)$ & $(-)$ & 16 & $\begin{array}{l}\text { MPD, } \\
\text { branch }\end{array}$ & Large & $(+)$ & $(+)^{5}$ \\
\hline 8 & $76 / M$ & 10 & $\mathrm{~F}$ & 7.9 & $(+)$ & $(+)$ & $(-)$ & 95 & Branch & Small & $(-)$ & $(-)$ \\
\hline 9 & $62 / M$ & 8.5 & $\mathrm{~F}$ & 7.6 & $(+)$ & $(+)$ & $(+)$ & 36 & Branch & Moderate & $(-)$ & $(-)$ \\
\hline 10 & $50 / M$ & 8.5 & $\mathrm{~F}$ & 2.8 & $(+)$ & $(+)$ & $(+)$ & 47 & Branch & Small & $(-)$ & $(-)$ \\
\hline 11 & $73 / M$ & 8.5 & $\mathrm{~F}$ & 5.2 & $(-)$ & $(+)$ & $(-)$ & 25 & Branch & Moderate & $(-)$ & $(-)$ \\
\hline 12 & $56 / F$ & 8.5 & $\mathrm{~F}$ & 8.0 & $(-)$ & $(+)$ & $(+)$ & 78 & Branch & Small & $(-)$ & $(-)$ \\
\hline 13 & $56 / F$ & 8.5 & $\mathrm{~F}$ & 20.0 & $(+)$ & $(+)$ & $(+)$ & 72 & Branch & Small & $(-)$ & $(-)$ \\
\hline 14 & $73 / M$ & 7 & PT & 9.8 & $(-)$ & $(+)$ & $(-)$ & 21 & Branch & Small & $(-)$ & $(-)$ \\
\hline
\end{tabular}

${ }^{1}$ Type of plastic stent: $\mathrm{F}$, flaps at the both ends of the stent; PT, pig-tail roups at both ends of the stent.

2 Period since the initial diagnosis to the recognition of pancreatic stones.

${ }^{3}$ SD, Santorini duct; MPD, main pancreatic duct; branch, branch duct or pancreatic parenchyma.

${ }^{4}$ Number of pancreatic stones (small: $1-3$, moderate: $4-6$, large: $=7$ ).

${ }^{5}$ Patient 7 underwent endoscopic pancreatic duct drainage under increased amount of oral steroid intake. 
For reference, if the four patients with pancreatic stones detected at the initial diagnosis were included in this study, pancreatic shrinkage ratio $(0.61 \pm 0.10$ vs. $0.70 \pm 0.16, P=0.034)$ was revealed to be statistically significant, and narrowing of both Wirsung and Santorini duct $(\mathrm{OR}=5.09, P=0.057)$ was predominantly recognized in the pancreatic stone $(+)$ group by univariate analysis. The five factors which showed statistical significance in the univariate analysis were further analyzed by multivariate analysis with categorization of continuous variables (follow-up period: $\geq 5$ years vs. $<5$ years), which revealed only biliary stenting as a significant factor associated with pancreatic stones in patients with AIP (OR: 8.40, 95\%CI: $1.63-43.18, P=0.011$, by stepwise method) ( $\bullet$ Table 1).

\section{Size and duration of inserted plastic biliary stents}

The effects of biliary stent placement on the development of pancreatic stones were further investigated by comparing the caliber size and duration of the transpapillary-placed biliary stents. The stents were all plastic type [either $7 \mathrm{Fr}$. $\left(\mathrm{Zimmon}^{\circledR}\right.$, COOK Japan, Tokyo) or $8.5 \mathrm{Fr} . / 10 \mathrm{Fr}$. (Tannenbaum ${ }^{\circledR}$, COOK Japan)] and were endoscopically inserted without endoscopic sphincterotomy. The caliber size $(P=0.480)$ and period of stenting $(P=0.845)$ had no statistically significant effect on the occurrence of pancreatic stones ( $\bullet$ Table 2$)$.

\section{Location, number, and treatment of pancreatic stones} Demographic and clinical information on pancreatic stone $(+)$ patients are summarized in $\bullet$ Table 3. Pancreatic stone developed in the MPD or Santorini duct in seven patients and only in the branch duct or pancreatic parenchyma in seven patients. Recognition of a pancreatic stone after steroid initiation was significantly more rapid in patients with stones in the MPD or Santorini duct $(22.1 \pm 28.9$ months $)$ than in patients with stones developing elsewhere $(53.4 \pm 28.5$ months $)(P=0.018)$. Patients with pancreatic stones in the MPD showed an increased number of stones, with facilitating pancreatic atrophy even after the withdrawal of the biliary stents ( $\bullet$ Fig. 1 ) (Patient 4). No patient complained of uncontrollable weight loss due to chronic diarrhea or steatorrhea throughout the study period. Only one patient with stones that occluded the MPD developed a pain attack and needed endoscopic transpapillary pancreatic drainage and subsequent extracorporeal shock wave lithotripsy [22]. This patient underwent only a 5 Fr. naso-pancreatic duct drainage, as a plastic pancreatic stent could not initially be inserted through the severely stenotic MPD. The plastic stent was placed after increasing the amount of corticosteroid by $10 \mathrm{mg} /$ day (5 mg/day to $15 \mathrm{mg} /$ day) (Patient 7) ( Table 3).

\section{Discussion \\ $\nabla$}

Pancreatic stone is a key feature of the advanced phase of pancreatitis, commonly seen in conventional CP and AIP, as pancreatic stones are strongly associated with the occurrence of diabetes (relative risk of diabetes: 1.32 from Japanese nationwide study) [23] and severe pancreatic atrophy caused by occluded intraductal lithiasis and pancreatic juice stasis [24].

In patients with classical $\mathrm{CP}$, the incidence of pancreatic stones is $17-61 \%[25,26]$, with alcohol abuse [27] and smoking [26] considered to be risks. The mechanisms of developing alcoholic chronic pancreatitis are supported by several alcoholic effects determined in human and animal models: (i) the spasmogenic effect of the Oddi sphincter accounting for the decrease in pancreatic secretion; (ii) increase in synthesis of lithostatine (pancreatic stone protein and glycoprotein-2) leading to the formation of fibrillar aggregates that might trigger protein and calcium precipitation [27]; (iii) dysfunction of the cystic fibrosis transmembrane regulator (CFTR) [28], a controller of the viscosity of pancreatic secretion; and (iv) activation of pancreatic stellate cells [29] that produce excessive extracellular matrix protein, an origin of the protein plug in the ductules [30]. Smoking effects on pancreatolithiasis were confirmed by an Italian epidemiological study by Cavallini et al. [26], who demonstrated that 66\% (376/ 570) of cases with CP developed pancreatic stones during 17 years of follow-up. In their study, smoking was a potent risk for pancreatolithiasis, independent of alcohol intake, and the mean period until the development of a pancreatic stone was 8 years in smokers compared to 12 years in non-smokers [26].

In patients with AIP, so far, relapse $[16,20]$, and narrowing of both Wirsung and Santorini ducts [15], with a high alcohol consumption ( $>50 \mathrm{~g} /$ day) [11] have been reported as risk factors for pancreatic stones. These factors also showed similar trends in the current study. Cases of AIP theoretically have additional risks supposed to cause pancreatolithiasis, such as long segments of narrowing of the pancreatic duct [15] and severe inflammation destroying pancreatic acini [12] and duct cells [28]. The narrowing stagnates pancreatic juice secretion and leads to formation of a protein plug and calcification [15]. Ko et al. [28] demonstrated misplacement of CFTR protein in the small duct cells of AIP, and proposed mechanisms that lead to decreased pancreatic $\mathrm{HCO}^{3-}$ secretion, which lowers the $\mathrm{pH}$ of pancreatic juice and ultimately causes a pancreatic stone to form. In contrast, Ito et al. [12] compared pancreatic exocrine function between AIP and classical CP, and demonstrated that secretion volume and amylase output were largely repressed in AIP, whereas $\mathrm{HCO}^{3-}$ concentration was relatively preserved in cases of AIP. Once developed in the MPD or Santorini duct, pancreatic stones worsened pancreatic exocrine and endocrine function with a rapid increase in the number of pancreatic stones ( $\bullet$ Fig. $1 ;$ Table 3 ). Therefore, cause and mechanism need to be further clarified in cases of AIP.

An international investigation of 1064 patients with AIP collected from 10 countries revealed that pancreatic stones were recognized in only $7 \%$ of cases, specifically in type 1 AIP, and more frequently in relapse cases than in non-relapse cases (14.4\% vs. $4 \%$, $P<0.001$ ) [20]. In Japan, where type 1 AIP accounts for most of the cases, the occurrence of pancreatic stones has been reported in $18.3-40.6 \%[11,15]$ of AIP. The pancreatic stones in the present study were associated with the follow-up period ( $\bullet$ Table 1 ) and developed at different times during the long period of the clinical course ( Table 3 ). Hence, the differences in their incidence may have arisen from the different follow-up periods (minimum: $\geq 1$ year [11] and $\geq 3$ years [15], respectively and average: 76 months [11] and median 91 months [15], respectively). In the current series, the incidence of pancreatic stones was $28 \%(14 / 50)$ in AIP cases with a minimum $\geq 1$-year and average 60-month follow-up period. We considered that this relatively high incidence of pancreatic stones might reflect some additional factors concerning institution-specific management of AIP patients, such as endoscopic management.

Despite the frequent use of stents in patients with biliary strictures $(71-77 \%)$ [20], biliary stent placement has not been studied in AIP. We had placed biliary stents without endoscopic sphincterotomy for as long as 9.0-10.6 months in AIP patients with jaundice and/or cholangitis ( $\bullet$ Table 2$)$ and demonstrated a 
risk of pancreatic stones by biliary stenting ( $\square$ Table 1 ). Our previous study revealed that biliary stenting without sphincterotomy was a significant risk for post-ERCP pancreatitis (OR: 3.0, $P=0.003$ ) [18], suggesting obstruction and/or stasis of pancreatic juice excretion from the major papilla. Especially in patients with narrowing of Wirsung and Santorini ducts and possibly in those with swelling of the papilla of Vater, severe stagnation of pancreatic juice was suggested when a biliary stent was placed without sphincterotomy. However, sphincterotomy against benign biliary diseases induces cholangitis or biliary symptoms (1.9-2.4\%) and cholecystitis (5.6-5.8\%) during long-term follow-up (82-90 months) [31,32]. To reduce the risk of pancreatic stone development without these iatrogenic events, use of corticosteroids is beneficial as it has an effect on the recanalization of biliary strictures. A steroid response can be obtained within 2 weeks in most cases with AIP $[7,8]$. Presumably, the ideal treatment strategy for jaundice and/or cholangitis in cases with AIP is a few weeks of biliary stenting without sphincterotomy in combination with steroid initiation. In cases with a mild level of jaundice, even biliary stenting may not be necessary if steroid treatment can be started in a suitable time. These cautions are especially needed with high alcohol consumption, relapse history, ERCP findings of swollen major papilla, and narrowing of both Wirsung and Santorini ducts. The current study has a limitation due to the small number of patients in a single tertiary hospital. Further studies are needed with a large number of AIP cases, comparing the known risk factors, to confirm the effect of biliary stenting against pancreatolithiasis.

\section{Competing interests: None}

\section{References}

1 Okazaki K, Yanagawa M, Mitsuyama T et al. Recent advances in the concept and pathogenesis of IgG4-related disease in the hepato-bilio-pancreatic system. Gut Liver 2014; 8: 462 - 470

2 Shimosegawa T, Chari ST, Frulloni L et al. International consensus diagnostic criteria for autoimmune pancreatitis: guidelines of the International Association of Pancreatology. Pancreas 2011; 40: 352 - 358

3 Kamisawa T, Chari ST, Lerch MM et al. Recent advances in autoimmune pancreatitis: type 1 and type 2. Gut 2013; 62: 1373-1380

4 Notohara K, Burgart LJ, Yadav D et al. Idiopathic chronic pancreatitis with periductal lymphoplasmacytic infiltration: clinicopathologic features of 35 cases. Am J Surg Pathol 2003; 27: 1119-1127

5 Matsubayashi $\mathrm{H}$, Uesaka K, Kanemoto $\mathrm{H}$ et al. Reduction of splenic volume by steroid therapy in cases with autoimmune pancreatitis. J Gastroenterol 2013; 48: 942 - 950

6 Matsubayashi H, Iwai T, Matsui T et al. Pancreatic cystic lesions with atypical steroid response should be carefully managed in cases of autoimmune pancreatitis. J Gastroenterol Hepatol 2016; 31: 270-276

7 Kamisawa T, Shimosegawa T, Okazaki K et al. Standard steroid treatment for autoimmune pancreatitis. Gut 2009; 58: 1504-1507

8 Matsubayashi $H$, Yoneyama M, Nanri K et al. Determination of steroid response by abdominal ultrasound in cases with autoimmune pancreatitis. Dig Liver Dis 2013; 45: 1034-1040

9 Nishimori I, Tamakoshi A, Kawa S et al. Influence of steroid therapy on the course of diabetes mellitus in patients with autoimmune pancreatitis: findings from a nationwide survey in Japan. Pancreas 2006; 32: $244-248$

10 Hirano $K$, Isogawa $A$, Tada $M$ et al. Long-term prognosis of autoimmune pancreatitis in terms of glucose tolerance. Pancreas 2012; 41: 691 695
11 Hirano $\mathrm{K}$, Tada $M$, Isayama $\mathrm{H}$ et al. High alcohol consumption increases the risk of pancreatic stone formation and pancreatic atrophy in autoimmune pancreatitis. Pancreas 2013; 42: $502-505$

12 Ito T, Kawabe K, Arita $Y$ et al. Evaluation of pancreatic endocrine and exocrine function in patients with autoimmune pancreatitis. Pancreas 2007; 34: $254-259$

13 Frulloni L, Scattolini C, Katsotourchi AM et al. Exocrine and endocrine pancreatic function in 21 patients suffering from autoimmune pancreatitis before and after steroid treatment. Pancreatology 2010; 10: $129-133$

14 Maruyama M, Watanabe T, Kanai $K$ et al. Extracorporeal shock wave lithotripsy treatment of pancreatic stones complicated with advanced stage autoimmune pancreatitis. BMC Gastroenterol 2015; 15: 28

15 Maruyama M, Arakura N, Ozaki Yet al. Risk factors for pancreatic stone formation in autoimmune pancreatitis over a long-term course. J Gastroenterol 2012; 47: 553-560

16 Takayama M, Hamano H, Ochi Yet al. Recurrent attacks of autoimmune pancreatitis result in pancreatic stone formation. Am J Gastroenterol 2004; 99: 932 - 937

17 Imai K, Matsubayashi H, Fukutomi A et al. Endoscopic ultrasonographyguided fine needle aspiration biopsy using 22-gauge needle in diagnosis of autoimmune pancreatitis. Dig Liver Dis 2011; 43: 869-874

18 Matsubayashi $H$, Fukutomi A, Kanemoto $H$ et al. Risk of pancreatitis after endoscopic retrograde cholangiopancreatography and endoscopic biliary drainage. HPB 2009; 11: $222-228$

19 Kubota K, Iida H, Fujisawa T et al. Clinical significance of swollen duodenal papilla in autoimmune pancreatitis. Pancreas 2007; 35: e51-60

20 Hart PA, Kamisawa T, Brugge WR et al. Long-term outcomes of autoimmune pancreatitis: a multicentre, international analysis. Gut 2013; 62: $1771-1776$

21 Sawai H, Matsubayashi H, Tanaka $M$ et al. A case of autoimmune pancreatitis with metachronous appearance of idiopathic thrombocytopenic purpura. Clin J Gastroenterol 2010; 3: 243-247

22 Matsubayashi $\mathrm{H}$, Kimura $\mathrm{H}$, Tobisu $\mathrm{K}$ et al. Autoimmune pancreatitis accompanied with recurrence of bladder cancer: difficulty in diagnosis and management of systemic lesions in a case with autoimmune pancreatitis. J Pancreas 2012; 13: 446-450

23 Ito $T$, Otsuki $M$, Itoi $T$ et al. Pancreatic diabetes in a follow-up survey of chronic pancreatitis in Japan. J Gastroenterol 2007; 42: 291 - 297

24 Nagai H, Ohtsubo K. Pancreatic lithiasis in the aged. Its clinicopathology and pathogenesis. Gastroenterology 1984; 86: 331 - 338

25 Lankisch PG, Otto J, Erkelenz I et al. Pancreatic calcifications: no indicator of severe exocrine pancreatic insufficiency. Gastroenterology 1986; 90: 617-621

26 Cavallini G, Talamini G, Vaona B et al. Effect of alcohol and smoking on pancreatic lithogenesis in the course of chronic pancreatitis. Pancreas 1994; 9: $42-46$

27 Vonlaufen A, Wilson JS, Apte MV. Molecular mechanisms of pancreatitis: current opinion. J Gastroenterol Hepatol 2008; 23: 1339-1348

28 Ko SB, Mizuno N, Yatabe Y et al. Corticosteroids correct aberrant CFTR localization in the duct and regenerate acinar cells in autoimmune pancreatitis. Gastroenterology 2010; 138: 1988-1996

29 Shimizu K. Mechanisms of pancreatic fibrosis and applications to the treatment of chronic pancreatitis. J Gastroenterol 2008; 43: 823-832

30 Witt H, Apte MV, Keim V et al. Chronic pancreatitis: challenges and advances in pathogenesis, genetics, diagnosis, and therapy. Gastroenterology 2007; 132: $1557-1573$

31 Costamagna G, Tringali A, Shah SK et al. Long-term follow-up of patients after endoscopic sphincterotomy for choledocholithiasis, and risk factors for recurrence. Endoscopy 2002; 34: 273-279

32 Doi S, Yasuda I, Mukai T et al. Comparison of long-term outcomes after endoscopic sphincterotomy versus endoscopic papillary balloon dilation: a propensity score-based cohort analysis. J Gastroenterol 2013; 48: $1090-1096$ 